This PDF is a selection from an out-of-print volume from the National Bureau of Economic Research

Volume Title: Risk Aspects of Investment-Based Social Security Reform Volume Author/Editor: John Y. Campbell and Martin Feldstein, editors Volume Publisher: University of Chicago Press

Volume ISBN: 0-226-09255-0

Volume URL: http://www.nber.org/books/camp01-1

Publication Date: January 2001

Chapter Title: Financial Engineering and Social Security Reform

Chapter Author: Zvi Bodie

Chapter URL: http://www.nber.org/chapters/c10597

Chapter pages in book: (p. 291 - 320) 


\title{
Financial Engineering and Social Security Reform
}

\author{
Zvi Bodie
}

President Clinton this week kicks off what he says will be a bipartisan effort to reform Social Security as interest groups line up with conflicting plans to save the national retirement system. . . . About three dozen groups announced last week they had joined forces to lobby for privatization, calling themselves the "Campaign to Save and Strengthen Social Security." Critics say such a plan is fraught with danger because benefits would depend on investment know-how and market swings.

-Donna Smith, reporter for Reuters, Washington, D.C., 6 December 1998

Suppose that we could introduce into the economic system any institutions we wish for shifting risks instead of being confined to those developed historically. . . . We would want to find a market in which we can insure freely against any economically relevant event. That is, an individual should be able to bet, at fixed odds, any amount he wishes on the occurrence of any event which will affect his welfare in any way. The odds, or, in a different and more respectable language, the premium on the insurance, should be determined, as any other price, so that supply and demand are equal. Under such a system, productive activity and riskbearing can be divorced, each being carried out by the one or ones best qualified.

- Kenneth Arrow, "Risk, Insurance, and Resource

Allocation," in Essays in the Theory of Risk Bearing (1971)

A major concern in the debate about replacing the current U.S. social security system with a system of self-directed personal investment ac-

Zvi Bodie is professor of finance and economics at the Boston University School of Management. 
counts (PIAs) is that ordinary Americans will not be able to cope with the complexities of providing for an adequate income in retirement by investing on their own. ${ }^{1}$ The proponents of PIAs point to the benefits of knowing the value of the funds in your own retirement account and having the freedom to make investment choices from an array of options. This investment choice would allow people to select a risk profile consistent with their own preferences and circumstances. But skeptics point out that the greater individual choice in PIAs also poses greater potential risks.

Economists cringe at the suggestion that increasing the choices available to people can make them worse off. If the new set of choices includes the status quo as one alternative, goes the reasoning, then surely one's welfare cannot decrease. This paper attempts to show how to make the economist's reasoning work in the context of PIAs. It seeks to show how government and private-sector financial institutions can offer people a menu of investment choices that are at least as good as the ones they have now. The goal is to allow ordinary people to make informed investment decisions about risk-reward trade-offs and to implement those decisions at the lowest possible cost to themselves and society. Costs are defined to include not only explicit advisory fees or commissions but also the expenditure of one's own leisure time and the time and patience of friends and relatives in deciding how to invest. Social costs include possible market distortions arising from deceptive advertising or from unintended subsidies that may encourage suboptimal risk-taking behavior.

The paper is organized as follows. First, I examine the economic theory of optimal lifetime consumption and portfolio selection to see what guidance it offers for the investment of retirement savings. Then I show how to use financial engineering to produce a menu of investment choices defined by a guaranteed minimum level of benefits plus participation in a reference portfolio of stocks. I then consider the role of the government in implementing a system of private investment accounts. Finally, I critically examine some of the investment advice offered by investment-management firms.

\subsection{Life-Cycle Investing and Financial Engineering}

The economics literature on household portfolio selection over the life cycle is vast. While many of the scientific issues regarding how people actually make life-cycle investment decisions remain in dispute, much progress has been made in the past forty years in developing normative models of how such decisions can be made optimally. Those normative

1. In a recent study of the investment behavior of participants in TIAA-CREF, Bodie and Crane (1997) find some cause for "cautious optimism" about the ability of people to make informed choices about asset allocation. 
models are today being implemented by a relatively new branch of applied economics called financial engineering.

Financial engineering is the practical application of economic theory to the intertemporal allocation of resources and the management of risk. Its principal analytic tools are continuous-time stochastic optimization models and arbitrage-based models of contingent-claims pricing. In this section of the paper, I briefly summarize the development of financial engineering and its application to the investment-management business.

\subsubsection{Portfolio Optimization}

The application of economic theory to investment management began in 1952 with the Markowitz (1952) mean-variance theory. This theory provided a tractable model for quantifying the risk-return trade-off to be derived from a set of risky assets by identifying the standard deviation of a portfolio's rate of return as its risk and the mean as its reward. The inputs to the Markowitz portfolio-selection process consist of a set of risky assets characterized in terms of their means, standard deviations, and correlations with each other. The outputs are in the form of a menu of risk-return choices arrayed along an "efficient portfolio frontier."

Tobin (1958) added a risk-free asset to the list of inputs and showed how this expanded the efficient frontier and simplified the process of finding the optimal mix. Building on the work of Markowitz and Tobin, Sharpe (1964) and Lintner (1965) investigated the equilibrium structure of asset prices, and their capital asset pricing model (CAPM) became the basis for measuring the risk-adjusted performance of professional portfolio managers. $^{2}$ Today, the mean-variance model is at the core of quantitative models for asset allocation and can even be implemented on a personal computer.

In the late 1960s and early 1970s, models of optimal portfolio selection being developed in the academic world became considerably more sophisticated. Merton $(1969,1971,1975)$ introduced continuous-time stochastic models into portfolio theory, thereby extending and enriching the static, single-period mean-variance model. He showed that hedging can be as important as diversifying in the demand for assets. The desire to hedge against a risk gives rise to a demand for securities that are highly correlated with that risk. For example, a desire to hedge against adverse changes in short-term interest rates induces a demand for long-term bonds. Merton (1973b) also developed the multifactor intertemporal capital asset pricing model (ICAPM) and proved that, in equilibrium, a security's risk premium will reflect not only its beta on the market portfolio but also its betas on commonly shared hedging portfolios. ${ }^{3}$

2. For a more detailed account of these developments, see Bernstein (1992). Markowitz, Sharpe, and Tobin all were awarded Nobel Prizes in economics.

3. For references on dynamic portfolio theory and intertemporal capital asset pricing, see Merton (1992). 
The mean-variance approach to quantitative investment management was and is ideally suited to the structure of the mutual fund industry. Mutual funds provide the real-world counterparts to the optimally proportioned portfolios of the theory. Thus, Merton's ICAPM provides a theoretical rationale for investment firms to offer a "family" of optimal hedging portfolios suited to the needs of different clienteles. The firm can put various combinations of its member funds together in proportions that reflect the right mix for customers in various stages of the life cycle. These so-called life-cycle funds are then offered as final products.

\subsubsection{Options as Fundamental Building Blocks}

The practical role of options and other derivatives is perhaps best understood in the context of the state-preference theory of Arrow (1964) and Debreu (1959). The fundamental building blocks of this theory-known as Arrow-Debreu securities - are claims that pay $\$ 1.00$ contingent on a certain state of the world at a certain date and zero otherwise. The theory developed by Arrow and Debreu provided a general and useful framework for studying many issues in welfare economics and finance; however, until the early 1970s, it was believed that, because pure Arrow-Debreu securities have no real-world counterparts, people would not be able to observe their prices and use them for the allocation of resources and the management of risks.

That view started to change in 1973 with the dramatic discoveries in option-pricing theory by Black and Scholes (1973) and Merton (1973a) and the opening of the Chicago Board Options Exchange. ${ }^{4}$ The basic insight underlying these models is that a dynamic portfolio trading strategy in the stock can be found that will replicate the returns from an option on that stock. Hence, to avoid arbitrage opportunities, the option price must always equal the value of this replicating portfolio. The resulting pricing formula has only one input that is not directly observable: the volatility of the return on the stock.

Discovery of the option-pricing model and the technique of dynamic replication was soon followed by its extension to the theory and practice of investment management. Brennan and Schwartz (1976) applied it to the pricing of equity-linked life insurance, and Merton, Scholes, and Gladstein (1978) explored the performance of a portfolio in which 90 percent of the funds were invested in six-month commercial paper and the remainder used to purchase a portfolio of six-month call options on selected individual stocks. This idea was actually put to work with the formation of a new mutual fund, Money Market/Options. Leland (1980) wrote about and implemented a service that he called portfolio insurance. ${ }^{5}$

4. For the story of how these models were developed, see Scholes (1998) and Merton (1998).

5. Bernstein (1992) has a chapter devoted to these authors' ill-fated venture in portfolio insurance. 
Ross (1976), Breeden and Litzenberger (1978), and Banz and Miller (1978) showed that the prices of options could be used to derive the prices of the pure state-time claims envisioned by Arrow and Debreu. ${ }^{6}$

During the 1970s, exchanges were created to trade standardized futures and options contracts on major currencies, on U.S. Treasury bills and bonds, and on stocks. The success of these markets measured in terms of trading volume can be attributed in good part to the increased demand for managing risks in the volatile economic environment of the 1970s. This success in turn strongly affected the speed of adoption of quantitative financial models.

During the 1980s, the user base of financial engineering expanded greatly, becoming global in scope and including commercial and investment banks and institutional investors of all types, especially pension funds. Practitioners in financial institutions actually took on a major role in applied research, including the creation of proprietary databases, the development of new numerical methods for solving partial differential equations, and the implementation of sophisticated estimation techniques for measuring model parameters. By the late 1980s, the computational models used by practitioners in some investment firms became as sophisticated as any found in the academic journals. Indeed, the people developing these applied models were in many cases recruited from university finance departments.

\subsubsection{A Continuous-Time Model of Life-Cycle Financial Decisions}

In contemporary financial economics, the standard theoretical framework for analyzing life-cycle decisions is Merton's (1969, 1971, 1973a) continuous-time model of optimal consumption and portfolio choice. Merton's model is more general than the older Markowitz model of portfolio choice. The Markowitz model assumes that individuals make decisions "myopically" in a static single-period framework. Merton's model assumes that individuals make choices that maximize their expected utility from the consumption of goods and leisure over their lifetimes and that they are free to change their choices at any time.

There are several distinct time horizons in Merton's model. The planning horizon is the total length of time for which one plans. The time horizon for the retirement goal would be the balance of one's lifetime. Thus, for a twenty-five-year-old who expects to live to age eighty-five, the retirement planning horizon would be sixty years. As one ages, the planning horizon typically gets shorter and shorter.

The decision horizon is the length of time between decisions to revise the portfolio. The length of the decision horizon is controlled by the individual within certain limits. Some people review their portfolios at regular

6. Hakansson (1976) even proposed that financial intermediaries issue a type of ArrowDebreu security that he dubbed supershares. 
intervals - once a month (when they pay their bills) or once a year (when they file income-tax forms). People of modest means with most of their wealth invested in bank accounts might review their portfolios very infrequently and at irregular intervals determined by some "triggering" event such as getting married or divorced, having a child, or receiving a bequest. A sudden rise or fall in the price of an asset a person owns might also trigger a review of the portfolio. People with substantial investments in stocks and bonds might review their portfolios every day or even more frequently.

The shortest possible decision horizon is the trading horizon, defined as the minimum time interval over which investors can revise their portfolios. The length of the trading horizon is not under the control of the individual. Whether the trading horizon is a week, a day, an hour, or a minute is determined by the structure of the markets in the economy (e.g., when the securities exchanges are open or whether organized off-exchange markets exist).

To add more realism to Merton's model, Bodie, Merton, and Samuelson (1992) add a third choice variable - the amount of work people choose to do. In their model, individuals start out with an initial endowment of financial wealth and earning power from labor (their human capital). The market values of both components of wealth - financial and human capital - change continuously and stochastically. The wage rate (the return on human capital) is perfectly positively correlated with the market return on traded assets. ${ }^{7}$ Consumption, wealth, and rates of return are all denominated in real terms, that is, in units of the consumption good. At each point of time in the model, individuals determine the amount of their consumption, the proportion of their financial wealth to invest in risky assets (vs. the safe asset), and the fraction of their maximum possible labor income that they will "spend" on leisure so as to maximize their discounted lifetime expected utility.

The model's results indicate that the fraction of an individual's financial wealth optimally invested in equity should "normally" decline with age for two reasons. The first stems from the fact that human capital is usually less risky than equity and that the value of human capital usually declines as a proportion of an individual's total wealth as one ages. For example, in an individual's early years of work, her wealth is often dominated by relatively safe human capital so that a large share of her financial wealth should be in risky assets in order to get sufficient risk in her total wealth. ${ }^{8}$

7. While the assumption of perfect correlation is not entirely realistic, it greatly simplifies the development of the formal model.

8. Other theoretical models support the practical notion that the fraction in equity should normally decline with age. For a review of theoretical models that yield results similar to popular guidelines regarding the age-equity relation, see Samuelson (1994) and Jagganathan and Kocherlakota (1996). 
Second, at any given age, the greater the flexibility an individual has to alter her labor supply, the greater the amount she will invest in risky assets. Individuals may be able to offset changes in the value of their financial wealth by changing the amount they work. They may have the opportunity to work longer hours, take on extra jobs, or delay retirement. If younger workers have more opportunity to alter their labor supply than older workers, the share of assets held as risky equity should decline with age. ${ }^{9}$

\subsection{Personal Investment Accounts with a Guaranteed Floor}

The theory presented in the previous section is silent on the question of what institutions people will use or should use to achieve their optimal lifetime consumption plans. As we know, the mix of government-provided social security, employment-related pension plans, and other private saving in the provision of retirement income varies widely from country to country and even within each country. And it is precisely the question of the optimal institutional mix that is at the center of controversy in the ongoing debate about social security reform in the United States today.

But at least on one point there seems to be a consensus - participation in the reformed social security system should be mandatory, and there should be some minimum guaranteed level of real retirement benefits for everyone who pays into the system. There also seems to be a consensus that, at least for benefits in excess of the guaranteed level, people ought to have some portfolio choice. In the terminology of pension professionals, one can describe such a system as a floor plan-a defined-contribution plan with a defined-benefit minimum or floor level. Recently, Brennan and Cao (1996) have shown that, for uninformed investors, such payoff functions may be Pareto efficient. In this section of the paper, I show how to use stock-index options and option prices to produce personal investment accounts with this feature. ${ }^{10}$ As is customary, I divide the planning period into two parts: the accumulation phase before retirement and the postretirement phase where the accumulation is paid out as a lifetime annuity.

\subsubsection{The Preretirement Phase}

Options expand the menu of risk-return choices open to investors. Index options make it possible to combine downside protection with some upside tied to the performance of an underlying index portfolio. Investor interest in this kind of product has grown recently. In 1995, life insurance

9. It should also be noted that the safe asset in the Bodie, Merton, and Samuelson (1992) model is a bond whose interest and principal is denominated in units of the consumption good. Its real-world counterpart would therefore have to be a bond similar to the inflationprotected bonds issued by the U.S. Treasury in 1997.

10. For an earlier version of this idea, see Bodie and Crane (1999). 
Table 8.1

Stock-Index Call-Option Prices

\begin{tabular}{lccccc}
\hline & \multicolumn{5}{c}{ Exercise Price (\$) } \\
\cline { 2 - 6 } Mears to & 20 & 40 & 60 & 80 & 100 \\
\hline 1 & 80.98 & 61.95 & 42.94 & 24.59 & 10.45 \\
2 & 81.90 & 63.81 & 45.82 & 29.12 & 16.13 \\
3 & 82.79 & 65.58 & 48.62 & 33.19 & 20.92 \\
4 & 83.63 & 67.27 & 51.29 & 36.88 & 25.21 \\
9 & 87.25 & 74.61 & 62.57 & 51.72 & 42.36 \\
16 & 91.02 & 82.21 & 73.87 & 66.22 & 59.31 \\
25 & 94.28 & 88.70 & 83.40 & 78.44 & 73.84 \\
\hline
\end{tabular}

Note: These prices were computed using the Black-Scholes formula with $S=\$ 100, r=.05$, and volatility $=.2$.

companies in the United States began to offer five- to seven-year variable annuities that combined a floor with some upside. By 1997, some thirty insurance companies had introduced these products in the United States (e.g., KeyIndex annuities issued by Keyport, a division of Liberty Financial).

Table 8.1 shows prices of call options on a reference portfolio, expressed per $\$ 100$ share of the portfolio. ${ }^{11}$ The prices increase as the number of years to expiration increases and fall as the exercise price rises. For example, the entry $\$ 24.59$ in the next-to-last column of the first row is the price of a one-year call option on a $\$ 100$ share of a reference portfolio with an exercise price of 80 . The price is $\$ 29.12$ for an otherwise identical option with a maturity of two years (one row down), and it is $\$ 10.45$ if the option's exercise price is 100 (one column to the right).

Consider the risk-reward opportunities available to people who divide their wealth between call options and risk-free bonds maturing on the same date that the options expire. These investors are guaranteed a certain minimum rate of return by virtue of the fact that a fraction of their wealth is invested in the risk-free asset, and they cannot lose more than they invest in the options. The reward is the potential additional return that can come if the calls end up "in the money."

The investor's exposure to risk depends on three variables: the exercise price of the calls $(X)$; the fraction of wealth invested in calls $(w)$; and the maturity of the calls $(T)$. A trade-off between reward and risk exists along each of these three dimensions of choice. Equation (1) expresses the basic formula that relates the investor's terminal wealth to the value of the refer-

11. Long-term options such as these are called LEAPS, an acronym for long-term equity anticipation securities. Options on the S\&P 500 are traded on the Chicago Board Options Exchange under the symbol SPX. They are European-type options, which means that they can be exercised only at their expiration date. 
ence portfolio on the option's expiration date and to the three choice variables- $X, w$, and $T$ :

$$
\frac{W_{T}}{W_{0}}=(1-w) e^{r T}+\frac{w}{C(X, T)} \max \left[100 \frac{S_{T}}{S_{0}}-X, 0\right],
$$

where $W_{T}$ is the investor's wealth at time $T, r$ is the risk-free interest rate, $C(X, T)$ is the price of a call with exercise price $X$ expiring at time $T$, and $S_{T}$ is the value of the reference portfolio at time $T$. For ease of interpretation, I make the following transformation from values to annualized continuously compounded rates:

$$
R \equiv \frac{1}{T} \ln \left(\frac{W_{T}}{W_{0}}\right)
$$

where $R$ is the portfolio's rate of return.

Let us examine each of the risk-reward trade-offs one at a time.

\section{Payoff Diagrams}

First, consider the trade-off arising from the choice of exercise price. The exercise price determines the threshold value of the market index, that is, the value of the index that must be reached in order for the call option to wind up "in the money" at expiration. The higher this threshold value, the greater the client's exposure to risk. However, since the price of the call falls when $X$ rises, the client's upside participation rate rises along with the increase in risk exposure. Thus, there is a trade-off between risk and reward.

To derive the formula for the payoff function relating $R$ and $X$, substitute into equation (1) the values $w=.10, r=.05$, and $T=1$ to get

$$
\frac{W_{1}}{W_{0}}=.9 e^{.05}+\frac{.1}{C(X, 1)} \max \left[100 \frac{S_{1}}{S_{0}}-X, 0\right] .
$$

Figures 8.1 and 8.2 illustrate the effect of changing $X$. Figure 8.1 shows the client's rate of return as a function of the value of the reference portfolio for different exercise prices. The curves all have the kinked shape characteristic of call-option payoff diagrams. In every case, the investment manager invests 90 percent of the client's wealth in the risk-free asset and 10 percent in stock-index calls. ${ }^{12}$ The minimum rate of return on the portfolio is therefore the same in all cases: -5.5 percent.

12. Note that a call option with an exercise price of zero is equivalent to the stock itself if the stock pays no dividend over the life of the option. 


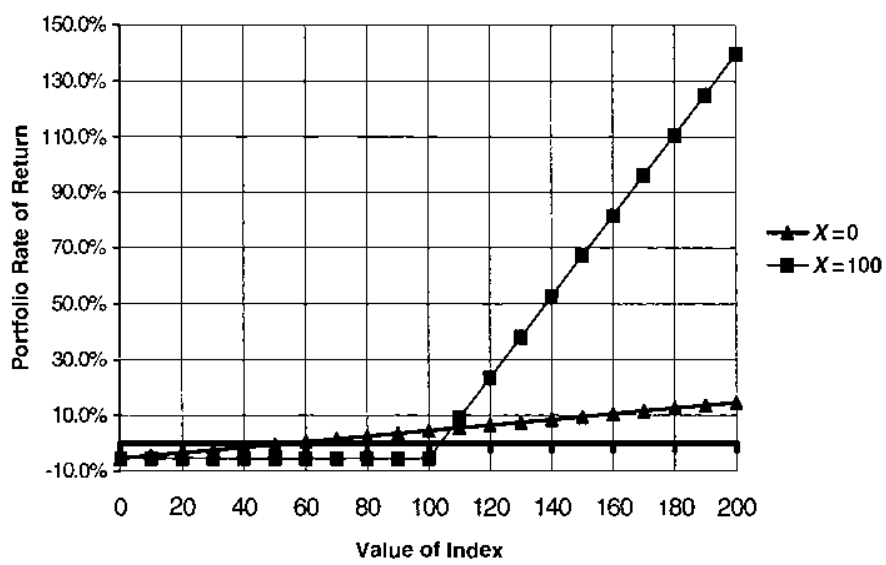

Fig. 8.1 Payoff diagrams with different exercise prices

Note: The portfolio has 90 percent invested in the risk-free asset earning 5 percent and the other 10 percent invested in calls with exercise price $X . T=$ one year, and $\sigma=.2$.

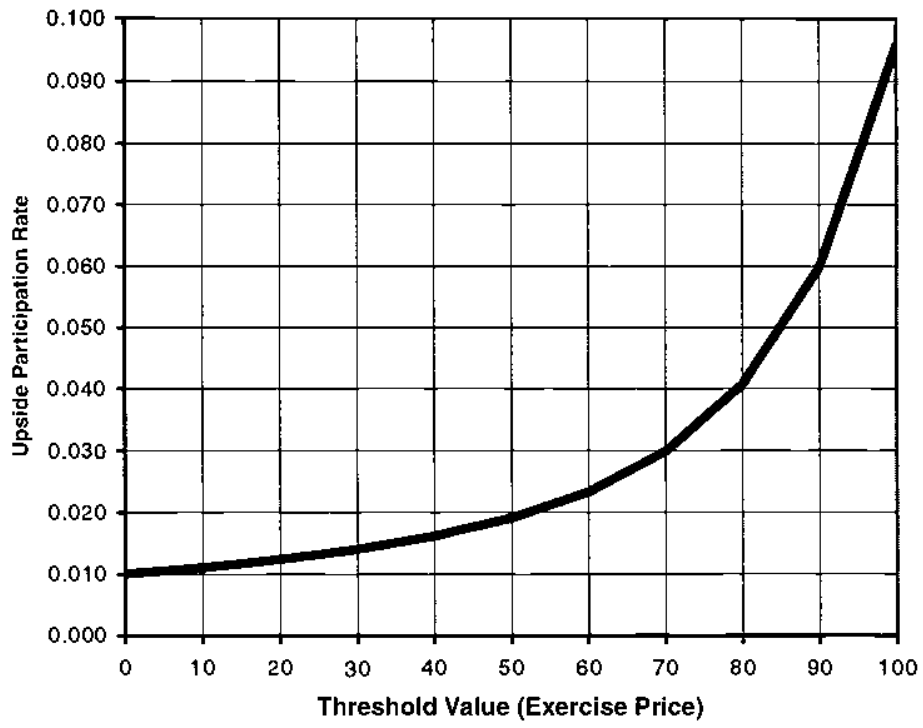

Fig. 8.2 Trade-off between exercise price and participation rate

The higher the exercise price, the steeper the slope to the right of the kink. This slope is the upside participation rate. For example, if $X$ is set at 80 , the option price is $\$ 24.59$, and the upside participation rate is .004 . If $X$ is set at the current level of the reference index $(X=100)$, then the upside participation rate is approximately .010. This trade-off between threshold value $(X)$ and upside participation is shown in figure 8.2. 


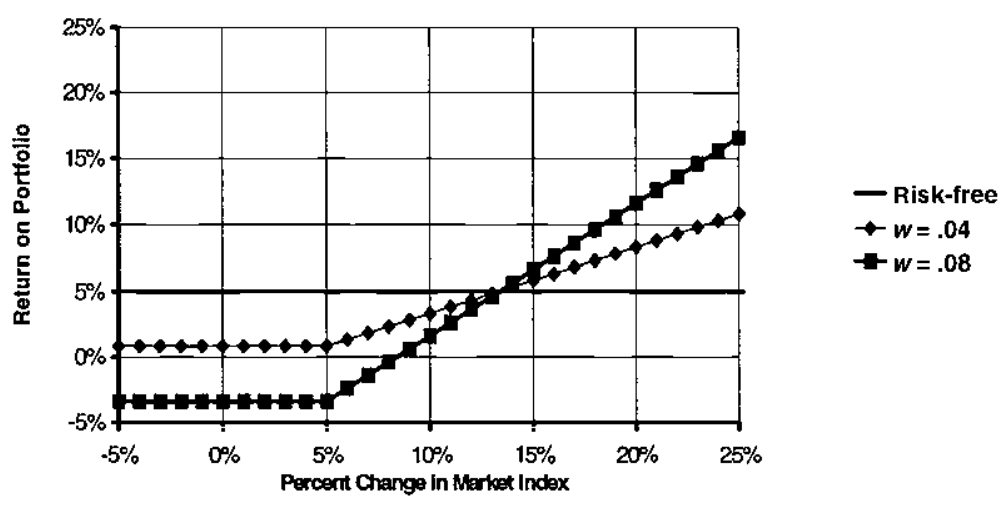

Fig. 8.3 Payoff diagrams with different amounts of wealth at risk

Note: $r=5$ percent, $T=$ one year, $X=100 e^{.05}$, and $C=8$. All the payoff functions meet in a common intersection point, whose coordinates are 13.4 and 5 percent.

\section{Risk and Reward in an Options Framework}

Now consider what happens if we vary the minimum return $\left(R_{\min }\right)$ by changing the fraction of wealth at risk $(w)$, holding constant the other two choice variables $-X$ and $T$. Figure 8.3 shows the portfolio rate of return as a function of the percentage change in the underlying stock index when $r=5$ percent, $T=$ one year, $X=100 e^{.05}$, and $C=8$.

Each curve corresponds to a different level of $w$. The vertical intercept is the minimum rate of return on the portfolio, and the slope of each payoff curve to the right of the kink is the corresponding upside participation rate. The higher the value of $w$, the lower the minimum return, and the higher the upside participation rate. For all three curves, the kink occurs at the risk-free rate of 5 percent per year because, if the percentage increase in the market index turns out to be less than this, the calls expire worthless. Note that all three payoff curves meet in a common break-even point, where the percentage increase of the market index is 13.4 percent and the portfolio return equals the risk-free interest rate. ${ }^{13}$

The risk-reward trade-off frontier shown in figure 8.4 corresponds to $T=$ one year and $X=100 e^{.05}$. The Black-Scholes price of the corresponding call is 8. In figure 8.4, the $R_{\min }$ is measured on the horizontal axis, and the upside participation rate is measured on the vertical axis. The slope of this trade-off line is the reward-to-risk ratio.

\section{Effect of the Time Horizon on the Risk-Reward Trade-Off}

As discussed in section 8.1.3 above, one can distinguish at least two different meanings of the term time horizon: the planning horizon and the

13. More generally, this intersection point occurs where $S_{T} / S_{0}=e^{r}(1+C / 100)$. 


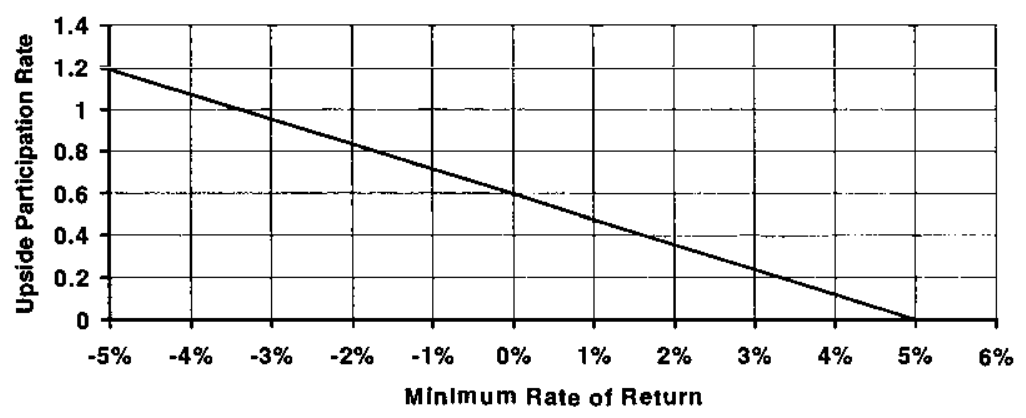

Fig. 8.4 The risk-reward trade-off frontier

decision horizon. The planning horizon is the total length of time for which one plans. The decision horizon is the length of time between decisions to revise the portfolio. The shortest possible decision horizon is the minimum trading interval over which investors can revise their portfolios. In this paper, as in other single-period models of portfolio selection, $T$ refers to the length of the decision horizon, not the length of the planning horizon.

The effect of the length of the time horizon $T$ for an investor who is willing to put 8 percent of his wealth at risk is shown in figure 8.5. Note that, the longer the length of the decision horizon, the worse the trade-off between risk and reward. For instance, the upside participation rate for a one-year period is 100 percent, for four years 50 percent, and for twentyfive years only 20 percent. This occurs because the call price $C$ is an increasing function of $T$ and asymptotically approaches 100 in the limit as $T$ gets larger and larger.

\subsubsection{The Postretirement Phase}

To this point, I have been discussing the accumulation phase of an investor's life cycle. Now I turn my attention to the postretirement phase of the life cycle, when the appropriate contract is a life annuity. I begin by explaining the way a variable annuity works. An assumed investment rate of return (AIR) is used to convert the total accumulation available at retirement into an annuity with a "notional" benefit payment, $B_{0}$. The annuity exceeds (falls short of) this notional value if the cumulative realized rate of return on the underlying reference portfolio exceeds (falls short of) the AIR. Each year, the amount received equals the previous year's benefit times a factor that reflects the actual compared to the assumed investment return:

$$
B_{t}=B_{t-1} \frac{1+R_{t}}{1+\mathrm{AIR}},
$$




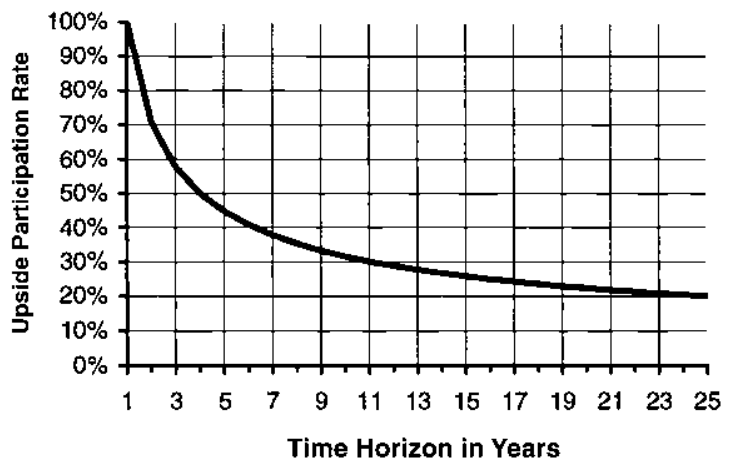

Fig. 8.5 Effect of time horizon on risk-reward trade-off Note: $w=.08, r=5$ percent, and $X=100 e^{.05}$.

where $R_{t}$ is the actual real rate of return on the underlying portfolio in year $t$.

Thus, after $t$ years of retirement, the annual benefit will reflect cumulative investment returns relative to the assumed return in each of the previous years of retirement:

$$
B_{t}=B_{t} \prod_{i=1}^{t}\left(\frac{1+R_{i}}{1+\mathrm{AIR}}\right) .
$$

With no loss of generality, we can divide both sides of this equation by the initial notional benefit and call the resulting number the cumulative return factor:

$$
\frac{B_{t}}{B_{0}}=\prod_{i=1}^{t}\left(\frac{1+R_{i}}{1+\mathrm{AIR}}\right)=\frac{\prod_{i=1}^{t}\left(1+R_{i}\right)}{(1+\mathrm{AIR})^{t}} .
$$

For simplicity, I use the risk-free real interest rate as the AIR. Assume that enough has been accumulated to qualify for a risk-free annuity of $\$ 10,000$ per year. Consider three alternative annuity designs: A risk-free real annuity of $\$ 10,000$ per year for twenty years; a variable annuity with a "notional" benefit payment $\left(B_{0}\right)$ of $\$ 10,000$; and a variable annuity with a floor and a cap. Figure 8.6 displays the payoff functions for the three alternative annuities as a function of the cumulative return factor. I assume a guaranteed floor equal to $\$ 7,000$, a risk-free real interest rate of 3.5 percent per year, and an annualized standard deviation of return on the underlying portfolio equal to 15 percent. The question is, What is the value of the cap for the third annuity design?

To address this question, I employ financial engineering. The first step 


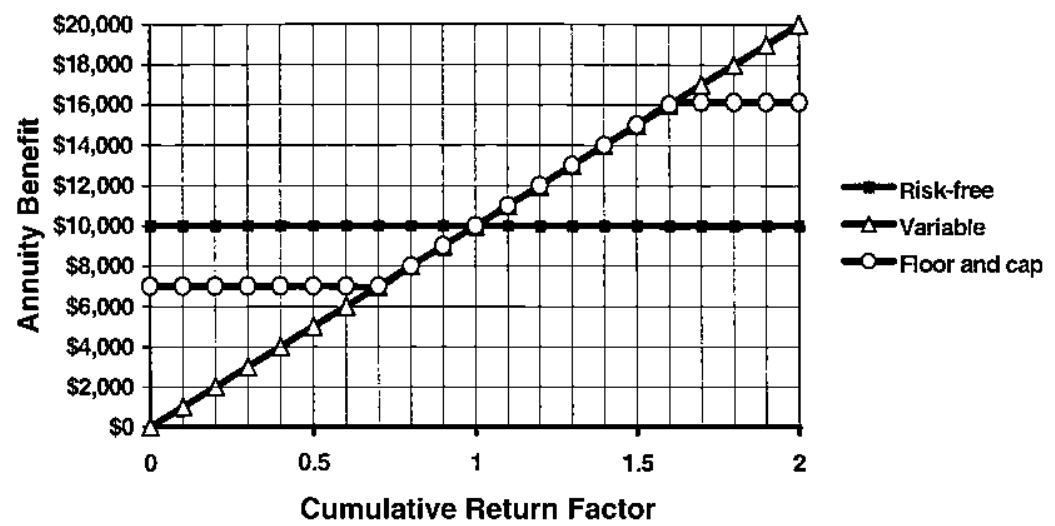

Fig. 8.6 Annuity payoff diagram

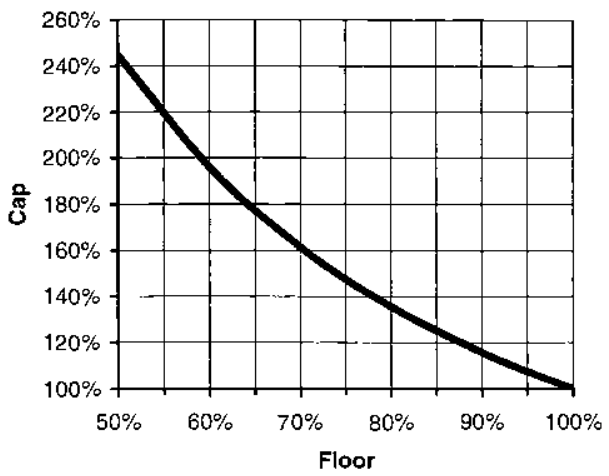

Fig. 8.7 Trade-off between the variable annuity floor and the cap

is to recognize that setting a floor and a cap on the variable benefit payment is equivalent to buying a "collar," that is, buying a European put option with an exercise price of $\$ 7,000$ and financing it by writing a call with a higher exercise price. ${ }^{14}$ Since the annuity consists of a sequence of twenty benefit payments, twenty collars are required, each with a maturity that is one year longer than the previous one. I compute the total price of the twenty puts using the Black-Scholes formula. Since each of the twenty annual payments is capped at the same level, the problem is to find the "exercise price" of the calls that will make their total price equal to the price of the puts.

Figure 8.7 shows the trade-off between the floor and the cap expressed as a percentage of the notional benefit. Thus, with the floor set at 70 per-

14. For a more complete explanation of collars, see Bodie, Kane, and Marcus (1999, 631-32). 
cent, the cap must be 161 percent. The higher the floor, the lower the cap. Of course, if the floor is set at 100 percent of the notional benefit, then the cap must also be set at 100 percent.

\subsection{The Role of Private-Sector Financial Institutions}

How can private-sector financial institutions provide credible guarantees of minimum real rates of return over long periods of time? The simplest organizational structure to perform this function would be that of a mutual fund or an investment trust that buys TIPS (Treasury inflationprotected securities) and index options and distributes a pro rata share to all its shareholders. The index options could be either exchange tradedif the required maturities are actually traded - or synthesized through dynamic replication. With such an organizational form, there can be no risk of default.

Alternatively, the institution could be organized as an insurance company that sells guaranteed investment contracts to its customers and has sufficient investor capital to make its liabilities free of default risk. To minimize the capital required for this purpose, the firm could hedge its liabilities dynamically using index futures contracts. The resulting dynamic hedges would be "model dependent" and therefore less than perfect. $^{15}$

\subsection{The Role of Government}

In addition to operating what remains of the current social security system and mandating minimum contributions to personal retirement accounts, there are at least two other important roles that have been proposed for the government: to issue inflation-protected bonds for people to invest in and to guarantee a minimum level of retirement benefits from PIAs.

\subsubsection{Inflation-Protected Securities}

The first of these is critical. ${ }^{16}$ The U.S. Treasury started issuing such bonds - TIPS — in January 1997, and policy spokesmen have made it clear that a primary purpose of these securities is to serve as a safe way for people to save for retirement. Their coupons and principal are linked to the CPI. Currently, the longest maturity is thirty years. Qualified financial institutions are allowed to "strip" them to offer customers zero-coupon bonds of any maturity up to thirty years.

15. For an analysis of the methods of making customer-held liabilities free of default risk, see Bodie and Merton (1992).

16. On this point, economists with policy views as diverse as Milton Friedman and James Tobin are in agreement. 
In September 1998, the Treasury started selling a new type of inflationprotected savings bond, Series I, which is targeted at lower- and middleincome people. I bonds offer a fixed real rate of interest, which can be extended at the investor's option for up to thirty years. They are tax deferred until cashed in, come in denominations as small as $\$ 50$, and can be purchased with no commissions. Individuals are limited to buying a maximum of $\$ 30,000$ worth of them per year.

Merton (1983) has proposed that a superior alternative to indexing retirement annuities to the cost of living is to index them to aggregate per capita consumption. The idea motivating this proposal is that it is standard-of-living protection rather than cost-of-living protection that is of prime concern to most individuals. With a cost-of-living-linked annuity, the benefit is fixed in real terms regardless of what happens to the standard of living in the economy. Individuals receiving a cost-of-living annuity over a long period of retirement may experience a substantial decline in their relative standard of living compared to the rest of the population. According to the proposal, however, pensioners would receive a benefit that changes with per capita consumption, thus maintaining their relative standard of living.

Note that, with indexation to aggregate per capita consumption, there is no need to distinguish between the inflation and the real per capita consumption components of the change. The benefits are simultaneously protected against both. By linking the benefits to per capita consumption rather than the consumer price index, the pension scheme is made more consistent with both finance theory and common sense. One way to describe the per capita consumption annuity proposal is as a definedcontribution plan offering variable-annuity contracts based on an underlying portfolio of bonds that are indexed to aggregate per capita consumption. Merton envisions a major role for the government as a financial innovator in making this type of product possible by issuing consumptionindexed bonds that are free of default risk.

\subsubsection{Government Guarantees}

Given the existence of default-free TIPs of all maturities, it is hard to see the need for government guarantees of retirement income. Individuals desiring a risk-free retirement income can purchase these bonds or invest in retirement annuities that are collateralized by these bonds. Other methods of guaranteeing retirement income have significant costs (see Bodie and Merton 1992). For example, in the United States, the federal government provides guarantees of corporate defined-benefit pensions through the Pension Benefit Guaranty Corporation. ${ }^{17}$ Let us consider some general

17. For an analysis of the Pension Benefit Guaranty Corporation's guarantee program, see Bodie and Merton (1993) or Bodie (1996). 
issues that inevitably arise when government serves as the guarantor of such household assets.

In the past, some among both the general public and politicians have mistakenly believed that a loan guarantee costs the government nothing unless there eventually turns out to be a shortfall. ${ }^{18}$ However, perhaps owing to the large losses in the deposit insurance funds, such arguments seem to appear less frequently now. Indeed, since 1990, the U.S. government has taken steps in its budget process to account for the cost of the guarantees it issues (see OMB 1993).

Even if it recognizes the cost of its guarantees, the government is not obliged to price them accordingly. There can be political pressure for the government to charge less than the fair market premium for its guarantees or not to charge for them at all. Government guarantees are a politically attractive form of expenditure because they are less "visible" than outright cash outlays or budget allocations. To keep premiums low, the government must require the insured entity to hedge its insured liabilities completely. If the imposition of strict asset restrictions by the government guarantor is also ruled out, then the guarantor is left with no feasible way to perform its guarantee function efficiently.

\subsection{Conventional Investment Advice and Economic Theory}

There are many sources of advice for investors, including newspaper columns, magazine articles, and web sites on personal investing. In addition, educational materials are provided by mutual fund groups and other providers of financial products. While there are some differences in advice provided by these various sources, a nonexhaustive search indicates that they generally agree on a set of practical guidelines, which can be summarized as follows:

- Investors should have an emergency fund invested in short-term safe assets. This fund should be held outside one's retirement account to avoid the tax and other penalties generally associated with having to withdraw funds prematurely from a retirement account.

- Tax-advantaged assets, such as municipal bonds, should be held outside one's retirement account, and only investors in high tax brackets should invest in them at all.

- Funds saved for retirement should be invested primarily in equities and longer-term fixed-income securities.

- The fraction of assets invested in equities should decline with age. A popular rule of thumb regarding the age-equity relation is that the per-

18. If applied to the private sector, this same mistaken belief would imply that insurance companies do not incur a liability when they issue policies, only when there are actual damage claims. 
centage of one's portfolio to invest in equities should be 100 minus one's age. So a person thirty years old should invest 70 percent in equities, and a person aged seventy should invest 30 percent in equities.

- The fraction invested in equities should increase with wealth because a wealthier individual should be able to handle more risk.

This practical advice can be derived from theoretical models similar to the ones presented in section 8.1 above by making suitable assumptions about either the investor's utility function, external borrowing constraints, or the stochastic processes governing security returns.

Nonetheless, there are some elements in the reasoning used to support the conventional advice that contradict economic theory. The two I focus on here are the ones that have the most potential to distort policy decisions in all sectors (households, firms, and government agencies): Stocks are less risky in the long run than in the short run, and stocks are a good hedge against inflation in the long run.

These propositions lead people to think that, the longer their planning horizon, the higher the fraction of their money they should invest in equities. As an example, consider the following "educational" information that appears at the Vanguard Group's web site: "In your early and middle working years, when your investment horizon extends 40 years or more, your primary investment objective should be to accumulate capital for your retirement. At this point in your life, common stocks should be your dominant investment option, for two reasons: Stocks have provided the highest long-term total returns of any major asset class. While stocks also have had the highest volatility level of any asset class, the passage of time has a dampening effect on their short-term fluctuations."

Since the 1960s, Paul Samuelson $(1963,1971,1989,1994)$ has been demonstrating the logical flaw in this reasoning. Using option-pricing theory, I, too, have tried - with little success - to persuade professional investment managers that it is a mistake to think that stocks are less risky in the long run than in the short run (see Bodie 1995).

I think that one reason that so many people still make the mistake is that they (at least implicitly) define investment risk as the probability of earning less than some target rate of return. In the practitioner literature, this probability is called shortfall risk. It is indeed true that, if the assumed expected rate of return on stocks exceeds the target rate of return, the probability of a shortfall does indeed decline as the time horizon lengthens. But the probability of a shortfall is a flawed measure of risk because it completely ignores how large the potential shortfall might be. A measure of risk should take account of both the probability and the magnitude of the potential shortfall (see Harlow 1991).

The proposition that stocks are a good inflation hedge relies on the fallacious belief that stocks are not risky in the long run. An inflation 
hedge would allow one to lock in a certain amount of purchasing power at a future date with certainty. As discussed before, the asset with that feature is an inflation-indexed bond maturing on the future date. Stocks do not promise a sure inflation-protected return over any time horizon.

Another reason that people fall into the trap of thinking that stocks are not risky in the long run is that they rely on faulty statistical inference. They are persuaded by the stock market history of the United States and the United Kingdom that, with virtual certainty, stocks will outperform bonds over long periods. There are at least three arguments against drawing such an inference from the historical data. The first is the small number of independent observations of long-period returns; the second is survivorship bias; and the third is that bonds in the past were not protected against inflation.

\subsection{Summary and Conclusions}

As the world's population ages over the next few decades, governments will shift from pay-as-you-go systems of social security to mandatory selfdirected retirement accounts. A major challenge facing the financial services industry is to help people manage the risks of investing for their own retirement. One strategy that is likely to succeed is to provide new contracts for long-term saving that combine the best features of definedcontribution and defined-benefit pension plans.

This paper has attempted to show that financial intermediaries can offer personal investment accounts that "replicate" the best features of definedbenefit pensions. These accounts could offer some choice regarding participation in the "upside" potential of the stock market without jeopardizing the minimum level of benefits mandated by law. It has also attempted to show that the existence of inflation-protected U.S. Treasury bonds makes government guarantees of personal investment accounts unnecessary, that guaranteeing investments in common stocks against the risk of a "shortfall" can be very costly and creates the potential for moral hazard, and that government can play a (perhaps unique) role in enriching the investment opportunity set by issuing securities that are linked to an index of per capita consumption spending.

\section{References}

Arrow, Kenneth. 1964. The role of securities in the optimal allocation of riskbearing. Review of Economic Studies 31, no. 2 (April): 91-96.

Banz, R. W., and M. H. Miller. 1978. Prices for state contingent claims: Some estimates and applications. Journal of Business 51, no. 4 (October): 653-72. 
Bernstein, Peter L. 1992. Capital ideas. New York: Free Press.

Black, Fischer, and Myron S. Scholes. 1973. The pricing of options and corporate liabilities. Journal of Political Economy 81 (May-June): 637-54.

Bodie, Zvi. 1995. On the risk of stocks in the long run. Financial Analysts Journal 51, no. 3 (May/June): 18-22.

1996. What the Pension Benefit Guaranty Corporation can learn from the Federal Savings and Loan Insurance Corporation. Journal of Financial Services Research 10, no. 1 (January): 83-100.

Bodie, Zvi, and Dwight B. Crane. 1999. The design and production of new retirement savings products. Journal of Portfolio Management 25, no. 2 (winter): $77-82$.

Bodie, Zvi, Alex Kane, and Alan B. Marcus. 1999. Investments. 4th ed. Burr Ridge, Ill.: Irwin/McGraw-Hill.

Bodie, Zvi, and Robert C. Merton. 1992. On the management of financial guarantees. Financial Management 21 (winter): 87-109.

1993. Pension benefit guarantees in the United States: A functional analysis. In The future of pensions in the United States, ed. R. Shmitt. Philadelphia: University of Pennsylvania Press.

Bodie, Zvi, R. C. Merton, and W. Samuelson. 1992. Labor supply flexibility and portfolio choice in a life-cycle model. Journal of Economic Dynamics and Control 16:427-49.

Breeden, D., and R. Litzenberger. 1978. Prices of state-contingent claims implicit in option prices. Journal of Business 51, no. 4 (October): 621-51.

Brennan, Michael J., and H. Cao. 1996. Information, trade, and derivative securities. Review of Financial Studies 9:163-208.

Brennan, Michael J., and E. Schwartz. 1976. The pricing of equity-linked life insurance policies with an asset value guarantee. Journal of Financial Economics 3 (June): 195-214.

Brown, Stephen J., W. N. Goetzmann, and S. A. Ross. 1995. Survival. Journal of Finance 50, no. 3 (July): 853-73.

Debreu, G. 1959. Theory of value. New York: Wiley.

Goetzmann, W. N., and P. Jorion. 1999. A century of global stock markets. Journal of Finance 54 (June): 953-80.

Hakansson, N. H. 1976. The purchasing power fund: A new kind of financial intermediary. Financial Analysts Journal 32, no. 6 (November/December): 2-12.

Harlow, W. V. 1991. Asset allocation in a downside risk framework. Financial Analysts Journal (September/October): 28-40.

Jagganathan, R., and N. R. Kocherlakota. 1996. Why should older people invest less in stocks than younger people? Federal Reserve Bank of Minneapolis Quarterly Review 20, no. 3 (summer): 11-23.

Leland, Hayne E. 1980. Who should buy portfolio insurance? Journal of Finance 35:581-94.

Lintner, John. 1965. The valuation of risk assets and the selection of risky investments in stock portfolios and capital budgets. Review of Economics and Statistics 47 (February): 13-37.

Markowitz, Harry. 1952. Portfolio selection. Journal of Finance 7 (March): 77-91.

Merton, Robert C. 1969. Lifetime portfolio selection under uncertainty: The continuous-time case. Review of Economics and Statistics 51 (August): 247-57. Reprinted in Merton (1992).

- 1971. Optimum consumption and portfolio rules in a continuous-time model. Journal of Economic Theory 3 (December): 373-413. Reprinted in Merton (1992).

. 1973a. An intertemporal capital asset pricing model. Econometrica 41 (September): 867-87. Reprinted in Merton (1992). 
1973b. Theory of rational option pricing. Bell Journal of Economics and Management Science 4 (spring): 141-83. Reprinted in Merton (1992).

. 1975. Theory of finance from the perspective of continuous time. Journal of Financial and Quantitative Analysis 10 (November): 659-74.

. 1983. On consumption indexed public pension plans. In Financial aspects of the United States pension system, ed. Zvi Bodie and John B. Shoven. Chicago: University of Chicago Press.

1992. Continuous-time finance. Rev. ed. Oxford: Blackwell.

1998. Applications of option-pricing theory: Twenty-five years later. American Economic Review 88, no. 3 (June): 323-49.

Merton, Robert C., Myron S. Scholes, and M. Gladstein. 1978. The returns and risk of alternative call option portfolio investment strategies. Journal of Business 51 (April): 183-242.

Office of Management and Budget (OMB). 1993. Identifying long term obligations and reducing underwriting risks. In Budget of the US government for 1993, section 13. Washington, D.C.: U.S. Government Printing Office.

Ross, Stephen A. 1976. Options and efficiency. Quarterly Journal of Economics 90 (February): 75-89.

Samuelson, Paul A. 1963. Risk and uncertainty: A fallacy of large numbers. Scientia (April-May): 1-6.

. 1971. The fallacy of maximizing the geometric mean in long sequences of investing or gambling. Proceedings of the National Academy of Science, 207-11.

.1989. The judgement of economic science on rational portfolio management: Timing and long-horizon effects. Journal of Portfolio Management (fall): $4-12$.

1994. The long-term case for equities and how it can be oversold. Journal of Portfolio Management 21, no. 1 (fall): 15-24.

Scholes, Myron S. 1998. Derivatives in a dynamic environment. American Economic Review 88, no. 3 (June): 350-70.

Sharpe, William F. 1964. Capital asset prices: A theory of market equilibrium under conditions of risk. Journal of Finance 19 (September): 425-42.

Tobin, James. 1958. Liquidity preference as behavior towards risk. Review of Economic Studies 25 (February): 68-85.

\section{Comment Stephen A. Ross}

This is a simple paper in the best sense of the term. In a literature that has become ever more complex, this paper takes us back to the basics and grounds the problem of offering investment choices to social security participants in the bedrock of modern financial theory. It begins with a historical introduction that focuses on two central research areas, the continuous-time consumption-portfolio problem and the principle of spanning. The relevance of the continuous-time model of optimal savings and consumption behavior is obvious, but that of spanning may be less

Stephen A. Ross is the Franco Modigliani Professor of Finance and Economics at the Sloan School of Management, Massachusetts Institute of Technology, and a research associate of the National Bureau of Economic Research. 
so. It is well known that puts and calls span the space of opportunities. They are like Arrow-Debreu pure contingent claims that offer a dollar in a well-specified state of nature, but they are an interesting alternative in that they embody solutions to financial problems. Calls, for example, allow individuals to circumvent borrowing constraints and achieve a higher degree of leverage while retaining limited liability. More technically, they focus on the outcome of investments, that is, the distribution of returns, rather than on the artificial mathematically defined states in which outcomes occur.

It is useful to follow the pension literature and break the pension problem into the accumulation phase, during which savings takes place, and the payout phase, during which investments are harvested to finance consumption in retirement. Arguing that there seems to be consensus in the policy debate that any reform should leave social security mandatory and should have a minimum guarantee, the paper examines the use of investment accounts with explicit floors on performance during the accumulation phase - a principal guarantee - and participation in a stock index return above the floor. This is equivalent to combining a bond with a call option on the index. It is perplexing and ironic that, while in the United States we are just beginning to examine this as a potential structure for social security, it is a very popular private offering in Europe. (By some estimates, almost half of French bank accounts take this form.)

The form of this contract seems to have been shaped as much by the current debate as by the theory of consumption and portfolio choice over time. In general, having a guaranteed floor is equivalent to assuming that agents have infinite marginal utility below the cutoff level. Above the floor, this form is optimal only if the individual has a particular utility function (lognormal returns would require a constant-relative-risk-aversion utility function with particular parameters). It would be desirable to explore a bit further whether we really are comfortable with this as the appropriate form for preferences, although parsimony does seem to favor a contract with a floor and a linear participation in the index.

Using the standard Black-Scholes formula, the paper computes the value of these accounts for a grid of time horizons and guaranteed benefit floors. (There is a bit of a technical problem since the index pays no dividends and the formula should be adjusted, but this is easily patched.) Formally, if $w$ is the proportion that the account puts into the option component, then the terminal payoff at retirement will be $(1-w)$ times the amortized amount in the bond account and $w$ times the accumulation in the option, that is,

$$
(1-w) e^{r T}+[w / c(x, T)] \max \left[100\left(S_{T} / S_{0}\right)-x, 0\right],
$$

where $r$ is the interest rate, $c(x, T)$ is the value of a call option with maturity $T$ and exercise price $x$, and $100\left(S_{T} / S_{0}\right)$ is the ratio of the value of the 
index at time $T$ to that today at time 0 and where the current index level is taken to be 100 . Changing $x$ and $T$ allows us to trace out the sensitivity of this value to the parameters.

While this may seem like a simple exercise in option pricing, it is important to stress that it stands in sharp contrast to the usual methods for evaluating social security reforms. Typically, policy proposals are studied by simulating future investment returns and asking, for example, what level of funding will be required to sustain a given level of benefits with a given probability level. This is a bit like the value-at-risk approach often taken to examine the riskiness of a portfolio or a financial institution, and, while it is sensible, it is also highly dependent on a variety of assumptions about future stock return and, in particular, on the posited size of the equity-risk premium. There is currently a heated debate under way about whether the observed outperformance of the stock market is sustainable for the foreseeable future. The typical simulation methodology stakes policy on a presumption about that issue by drawing future returns from an estimate constructed from the historical record of market returns.

By contrast, the financial market approach advocated by Bodie asks a simpler question: Given the current pricing of financial securities, what is the cost of any particular policy composed of a floor return and an equity "kicker." In effect, this turns the focus of the equity-risk puzzle on its head. The question now becomes, not what the market will do in the future, but, rather, whether the market prices used to compute the value of the options are "correct." If the market is, in some sense, "too high," then that is a consequence of having realized a sequence of unsustainable returns that also, if used to project future returns, will result in an upwardly biased estimate of the risk premium on equities.

Despite this duality, for many questions the financial markets or optionpricing approach is clearly superior. Even if, in some equilibrium sense, we were all to agree that the current level of prices is appropriate, the traditional mode of analysis would still leave open the debate about what is the appropriate assumed future return on stocks. With the optionpricing approach, that rate plays no role in determining the current value of the strategy. In a real sense, the option approach does finesse the equityrisk-premium puzzle. Furthermore, insofar as there is to be a debate about whether the market is too high, any assumed level can be substituted for the current one to produce a different value for the strategy. But the intuitive "gut" check is simpler than that. The financial markets approach produces a clear price for any strategy, that is, the value it would have if one tried to replicate the payoffs with currently priced instruments. Whatever value emerges from that exercise is the price that such a strategy would cost if implemented by the private sector. Any analysis that produces a lower value, then, is tacitly assuming that private-sector pricing is wrong; that is, it is predicated on outguessing the market, and that would seem a rather precarious basis for public policy. (One could argue that the 
system would be so large that it would actually change pricing itself. While this is difficult to assess, such an effect would probably be marginal at most and is certainly highly conjectural.)

During the accumulation phase, the floor can be set in real terms, and the government issuance of inflation-linked bonds (or per capita consumption-linked bonds) provides a way of achieving a real guarantee. In the payout phase, the government can guarantee the minimum payout level, although Bodie sees little need for this given inflation-protected bonds. Bodie goes on to argue that the private sector could provide this service, given that the government has issued guaranteed linked bonds. Presumably, however, to hedge their liabilities, private institutions would have to rely in part on dynamic replication, and that is subject to model risk, gap-trading risk, and volatility and other parametric risks. For the system to work in an efficient way, there would have to be some form of regulation of these entities as well as private bonding and rating.

Given the economies of scope in such activities, the government would have to play a role-after all, ultimately, it is a government guarantee even if implemented by the private sector. However, given the history of problems with the government regulation of such guaranteed systems, from deposit insurance and savings and loans to guaranteed investment contracts, it would be naive to be sanguine about how well it would work. Equally important, to the extent to which individuals are given investment choices, there will be a demand for financial advice, and no doubt the financial advisory industry would expand dramatically in an effort to satisfy this demand. What is to be the role of government in this process is as yet unresolved. For example, if the government is to be an active purveyor of advice, presumably Bodie would have it side with those who argue that the fraction invested in equities, say, should decrease with age. This is much more obvious to Bodie than to me, particularly given that social security accounts are only a portion of total savings and, also, given the interaction between, for example, wealth and age.

There are, however, some more serious problems with a completely or partially privatized system with its attendant regulatory structure and the inevitable political pressures that will ensue. While I am very sympathetic to the idea of allowing individuals to invest for their retirement and, perhaps, have meaningful choices, I do not think that we can examine policy changes and ignore the political economic implications. Nor is this a matter of idle speculation; there have been significant historical examples from which we can learn.

I think that political pressure will manifest itself in at least two ways. First, if the system is to cost about the same as what we have today, then, inevitably, there must be a nonnegligible chance that a significant percentage of the participants will retire with less savings than they expected. Depending on the form of the system, this may mean that all or a large 
percentage will have earned only the real rate of return or some fraction of that. In either case, there will be a strong political motivation for the less-advantaged bloc to attempt to achieve through the political mechanism what they did not receive from the market. I have no particular wisdom on what to do about this problem, other than to acknowledge its existence. One thing is clear, however-by both practice and by law, the government seems bound to subgame perfection. That is to say, whatever circumstances it currently faces, the government must myopically seek the optimum. While that might seem desirable, it raises delicate incentive and time-consistency issues. For example, if the government could credibly commit to not aiding those whose investments led them to have less than a minimum amount, individuals might be encouraged to follow policies that kept them away from that floor. Since the government cannot commit not to help individuals in distress, it will always be forced to do so, and it must live with the consequences of individuals who recognize that they have a political "put" for their poor performance and act accordingly.

The only solution to this is to limit individual choices severely, but that raises the second and more subtle issue. When the system is privatized, individuals will be given account statements that detail "their" accumulations. When individuals reach retirement with a given level of accumulation, it may not be politically tenable to continue to deny them the ability to exercise their discretion in the payout phase. This was the experience of the TIAA-CREF system for financing pensions for employees in higher education. In response to individuals who felt that their investment options were too limited in the accumulation phase, TIAA-CREF has greatly expanded the available choices. With this has come the likelihood that the spread of individual performances will be much widened, and that has led to an attendant burden on financial education for participants in the system. In addition, many individuals were no longer content with the requirement that their accumulations be annuitized on retirement.

The first of these responses strongly suggests that, in the face of charges of paternalism, it will be politically difficult to restrain the range of choices open to individuals in the social security system. The second is equally devastating since it implies that it may not be possible to prevent some significant lump-sum distributions on retirement. (Even current tax penalties do not seem an adequate disincentive to prevent this from occurring.) To the extent to which the proceeds are not annuitized, the system no longer owns the ill health of its participants, and risk-averse individuals would have to oversave relative to an insurance system that operated as a tontine and would be subject to the vicissitudes of their own mortality.

Here, form may be as important as substance. Bodie argues that the guaranteed-floor system is usefully partitioned into a guarantee that is equivalent to an indexed bond and a call option on the equity return. This is equivalent (by put-call parity) to a contract that gives the return on an 
index with a put option at a specified level. In effect, individuals have the option to sell their portfolio back to the issuer-be it a private institution or the government - at a prespecified price. Perhaps, when results are bad, the fact that there is already an action that an individual can force on the government, that is, the put, would ameliorate some of the political pressure even though the numbers are the same. I suspect that this may be so, but, as a financial economist, venturing beyond the value equivalence of the two descriptions is further than I can go with any confidence.

Briefly concluding, then, the financial theoretic approach of Bodie is very appealing on both intellectual and practical grounds. The case is made most strongly for using it to evaluate the costs of proposed social security reforms, but the unresolved political financial issues make the case for the particular reform analyzed and, more generally, for a privatized system less clear.

\section{Discussion Summary}

Robert King remarked that, in a previous discussion, Thomas Sargent wondered why certain insurance instruments did not exist and noted that a similar puzzle applies here. About a dozen years ago, Chase Manhattan introduced a security that looked very much like the financial instrument proposed in the Bodie paper: it consisted of an account where the investor earned a particular interest rate and a portion of the market return if the stock market goes up. The accounts-return characteristics were based on Black-Scholes option-pricing principles. When the instrument was finally approved by the U.S. regulatory structure, its subsequent introduction was surprisingly unsuccessful. King noted that this is a major puzzle, which is crucial for the kind of proposal made in the paper. Maybe Chase Manhattan by itself was not able to offer the education that is also called for in the latter part of this paper; maybe there is something more fundamental that could explain the failure. He concluded that, in any event, the paper would benefit from examining that particular market experience in order to understand what actually happened.

John Campbell commented on the last section of the paper, dealing with conventional investment advice. First, Bodie contests Vanguard's statement that stocks appear to be less risky in the long run than in the short run. Campbell stated that the validity of that claim is an empirical issue, not a theoretical or logical one, as suggested in the paper. There is some evidence that the volatility of stocks rises with the horizon more slowly than would be implied by independently and identically distributed (i.i.d.) returns, which could be explained by mean reversion in stock returns. If 
stocks follow a mean-reverting process, then one can show that, for certain preferences, it is indeed optimal to invest more in stocks on average with a longer horizon. Of course, the mean reversion will also tend to generate market timing: one cannot obtain the positive horizon effect without also having the market timing. The entire topic of stocks for the long run involves quite some detail and subtlety. Campbell expressed the opinion that the treatment of the subject in the paper is too cavalier. The logical points that Samuelson made are "if-then" statements: if returns are i.i.d., and if people have power utility, then the horizon does not matter. But those logical arguments do not settle the practical issue of investing for the long run: that is by and large an empirical matter.

Relatedly, Campbell noted that the treatment of the Canner, Mankiw, and Weil (1997) (henceforth CMW) asset-allocation puzzle in the paper lacks detail. CMW point out that popular investment advice suggests that more conservative investors should have a higher ratio of bonds to stocks. This contrasts with standard mutual fund theorems that prescribe holding risky assets in a given proportion, regardless of risk aversion: more riskaverse people could simply add more cash to the mix and scale back on the mutual fund. As is mentioned in the paper, the explanation for this puzzle given by Brennan and Xia, bringing in intertemporal considerations, goes in the right direction. However, their explanation, ignoring inflation risk, is complete only to the extent that the conventional advice would concern real bonds. This is quite unlikely: the CMW paper was published before inflation-indexed bonds were available, and the investment advice analyzed certainly concerned nominal bonds. Therefore, the issue again becomes empirical: How close are nominal bonds to real bonds? Are they similar enough to justify the conventional advice, or does one need to modify the advice to stress real bonds rather than nominal ones? Campbell and Viceira (in press) report that it all depends. If one thinks that monetary policy will stay fairly stable as in the Greenspan era, then nominal and real bonds are sufficiently similar to rationalize the CMW puzzle using intertemporal considerations, ignoring inflation risk. The advice would be better for real bonds, but it is tolerable for nominal bonds. If, on the other hand, one thinks that there is a risk of going back to inflationary monetary policy, then the conventional advice is not correct and needs modification. Campbell concluded that there is a lot of empirical detail and that he worried that the paper ignores some crucial empirical questions, linking portfolio advice too closely to theoretical considerations.

Mark Warshawsky remarked that TIAA-CREF also considered offering financial products that combined real bonds with call options. They decided, however, that, at least at this stage, it is not feasible to do so because these long-term call options are very expensive. In response, King asked 
why long-term options are necessary. He added that Chase Manhattan's product was based on options with only one-year maturities.

Robert Shiller conjectured that only one- or two-year maturity options are traded, not long-term lifetime options, because most investors buy options for leveraging reasons, rather than to manage their lifetime security risk. An analogous issue is that people have virtually no interest in inflation-indexed bonds. They often complain that real bonds have not performed very well in recent years. Relatedly, an important explanation for the equity-premium puzzle, proposed by Benartzi and Thaler (1995), emphasizes that investors have very short horizons. This theory would be problematic for the ideas in the Bodie paper.

Henning Bohn pointed out that there is a caveat in the discussion of social security reform and financial engineering. Even if long-term call options were publicly traded, an important question to ask is who would be taking the opposite side of these option contracts. It seems important to consider aggregation and general equilibrium issues in this context.

James Poterba noted that Bodie is quite pessimistic about the ability of investors to make sound asset-allocation decisions. He and David Wise (Poterba and Wise 1998) reached a different conclusion in a paper that analyzed the investment decisions within 401(k) plans: except for the poor degree of diversification, the choices with respect to equity exposure did not seem totally anomalous. Poterba also noted that, although indexed bonds invested in a 401(k) or IRA plan earn a known real return, indexed bonds held in taxable accounts do not, both because of the uncertainty about the tax system and because the tax is based on the total cumulated nominal interest. This means that there is uncertainty about what the real after-tax return will be on withdrawal.

Following up on Poterba's first remark, David Cutler suggested adding a discussion concerning the tails of the distribution of individual investor choices. For instance, it would be interesting to mention what share of the investor population does not make sound investment decisions.

Martin Feldstein expressed the opinion that the link to social security benefits was missing in the paper. In particular, he gave the example of an individual who has to decide how much to save using these call options to eventually acquire the funds to buy the annuity that figure 8.6 reports. This calculation would be very interesting as it would allow the author to really offer investors finished financial products among which to choose.

Zvi Bodie responded first to Feldstein's question about how much an investor would have to save to achieve some target replacement rate and noted that the answer was straightforward only for investments at the risk-free rate. Any other investment, including call options, would be uncertain. Feldstein inquired about the case where the investor buys options to assure a certain probability of meeting the target. Bodie replied that, although 
Bodie and Crane (1999) considers precisely this, he is concerned about simulations reporting probabilities of achieving or not achieving some target. The problem is related to the disagreement between two papers presented earlier, that by Kent Smetters (chap. 3 in this volume) and that by Feldstein, Ranguelova, and Samwick (chap. 2 in this volume). Bodie argued that the probability of a shortfall is a very misleading measure of risk. It should be contrasted with the cost of insuring against the shortfall, which Bodie believed to be a superior measure: the probability of a shortfall does not consider the weight that one attaches to a shortfall or its severity. Instead, one should concentrate on Arrow-Debreu prices or riskneutral probabilities, following the insight from option-pricing theory.

With respect to Campbell's remark, Bodie agreed that the treatment in the paper of the proposition that stocks are less risky in the long run than in the short run could be considered too cavalier. He added, however, that his previous work with Robert Merton and William Samuelson (Bodie, Merton, and Samuelson 1992) offers a more detailed and careful analysis of the issue of life-cycle asset allocation and focuses, among other things, on the importance of human capital and labor supply flexibility. The paper is one example of the discussant's remark that the finance literature does not offer clear-cut and unambiguous answers to the question of optimal life-cycle portfolio choice. For instance, it is found that, under certain conditions, it is optimal to increase equity exposure as one ages, whereas, in other circumstances, older investors should hold less risky assets. Bodie concluded that, if anything is cavalier, it is the treatment of the subject by popular investment advisers, stating that, unambiguously and independently of preferences, stocks are less risky in the long run.

In response to King, Bodie noted that it is very rare in the history of the financial industry to find an innovation that has been successful immediately, except perhaps for money market funds, which succeeded from the outset, mainly because of Regulation Q and because of high short-term interest rates in the 1970s. Market conditions matter a lot. Bodie is optimistic about the prospects of the products proposed in the paper in the long run and refers to their success in Europe.

Regarding Shiller's comment that investors are reluctant to buy indexed bonds, Bodie replied that people change their investment behavior sluggishly. He added that part of the problem might be insufficient marketing efforts trying to make indexed bonds known to the general public.

Finally, David Wise replied to Shiller's comment, noting that long-term options do exist and are available as over-the-counter products. Moreover, they can be hedged relatively well dynamically using short-term options. Wise concurred with Bodie's discussion of the lack of initial success for many new financial products and gave the example of index funds. $\mathrm{He}$ further noted that indexed bonds might not gain popularity in a country like the United States characterized by relatively low and stable inflation. 


\section{References}

Benartzi, Shlomo, and Richard Thaler. 1995. Myopic loss aversion and the equity premium puzzle. Quarterly Journal of Economics 110:73-92.

Bodie, Zvi, and Dwight B. Crane. 1999. The design and production of new retirement savings products. Journal of Portfolio Management 25, no. 2 (winter): $77-82$.

Bodie, Zvi, R. C. Merton, and W. Samuelson. 1992. Labor supply elasticity and portfolio choice in a life-cycle model. Journal of Economic Dynamics and Control 16:427-49.

Campbell, John Y., and Luis M. Viceira. In press. Who should buy long-term bonds? American Economic Review.

Canner, Niko, N. Gregory Mankiw, and David N. Weil. 1997. An asset allocation puzzle. American Economic Review 87, no. 1:181-91.

Poterba, James M., and David A. Wise. 1998. Individual financial decisions in retirement savings plans and the provision of resources for retirement. In Privatizing social security, ed. Martin Feldstein. Chicago: University of Chicago Press. 